\title{
$\mathrm{PH} \mathbf{8} \mathbf{8}_{\text {ranorama }}$
}

\section{Mediaciones patrimoniales para relaciones incendiarias: el caso del santuario da Virxe da Barca de Muxía}

Este texto ${ }^{1}$ parte del análisis de un conflicto reciente en torno a un bien patrimonial que sufrió un incendio y que acaba de ser restaurado, el santuario da Virxe da Barca de Muxía. En este conflicto patrimonial se des-encuentran dos posturas; por una parte, gestores y técnicos de patrimonio, que han acometido una restauración siguiendo criterios expertos "desapasionados" y, por otra parte, la vecindad de Muxía, que reivindica formar parte de la gestión y del proceso de toma de decisiones sobre la restauración del bien como escenario político. En caso de conflictos y "relaciones incendiarias" como la sucedida en Muxía, proponemos la necesidad de una figura mediadora para facilitar la comunicación y comprensión mutua entre actores sociales e instituciones con ontologías patrimoniales diferentes: la mediación patrimonial.

Guadalupe Jiménez-Esquinas, Cristina Sánchez-Carretero | Instituto de Ciencias del Patrimonio (INCIPIT), Consejo Superior de Investigaciones Científicas (CSIC)

URL de la contribución <www.iaph.es/revistaph/index.php/revistaph/article/view/3633>

\section{El incendio}

El 25 de diciembre de 2013 el santuario barroco de la Virxe da Barca de Muxía (1717-1719) se incendió como consecuencia de un rayo, poco tiempo después de que el Instituto del Patrimonio Cultural de España (IPCE) finalizara su restauración. Unos días más tarde, el 6 de enero de 2014, la Pedra de Abalar, que forma parte de un conjunto de piedras neolíticas que funciona como referente simbólico y lugar fundacional de Muxía, se fracturaba como consecuencia de los temporales.

La relevancia de estos dos elementos para la gente de Muxía fue simbólicamente testada el 2 de agosto de 2013 cuando desde el INCIPIT y la asociación Niquelarte, con la colaboración del Proxecto Buserana desde el conceIlo, realizamos una actividad en la praza do Cabo da Vila en Muxía. En esta actividad se proponía un diagnóstico participativo sobre aquellos elementos patrimoniales más valorados y sobre los que se consideraba necesario una actuación o una reutilización. En la galería de diez elementos patrimoniales que proponíamos, el "santuario e romaría da Virxe da Barca" fue el elemento más seleccionado (65 personas) y el segundo fue la "pedra de Abalar e outras pedras da Barca" (47 personas). La mayoría de las personas que participaron definían el santuario y su romería, las piedras del entorno y todas las leyendas y los saberes asociados, como sus patri- monios más valiosos, como aquello que "ojalá nunca se perdiera".

La sucesión de hechos de las navidades 2013/2014 fue percibida como una auténtica desgracia por el pueblo de Muxía, que veía cómo los referentes patrimoniales más apreciados eran manejados a su antojo por las fuerzas de la naturaleza.

\section{El conflicto patrimonial}

El 26 de marzo de 2015, quince meses después de la destrucción del santuario de la Virxe da Barca, se celebraba la firma de recepción de la primera fase de unas obras de restauración cuyo costo ascendió a 736.324,76€. A este acto asistieron, por una parte, el representante del arzobispado, las representantes del estudio de arquitectura y encargadas de la obra que ganaron el concurso público, el sacerdote de la villa y representantes del ayuntamiento. Por otra parte, un nutrido grupo de personas que caldeaban el ambiente, increpando a los y las responsables por el resultado insatisfactorio de las obras que se entregaban.

Las imágenes de protesta y las quejas de los vecinos fueron recogidas en la prensa local y nacional y fueron imagen de portada en los telediarios nacionales. Micrófono en mano vecinas y vecinos de Muxía lanza- 
(6) Noticias Sociedad

DANOS DE GRAN ENVERGADURA

\section{Un Incendio arrasa el santuario de A Virxe da Barca, en Muxía}

Un incendio se ha declarado en el emblemático santuario de A Virxe da Barca, en el municipio coruñés de Muxia, informaron fuentes de la Xunta.

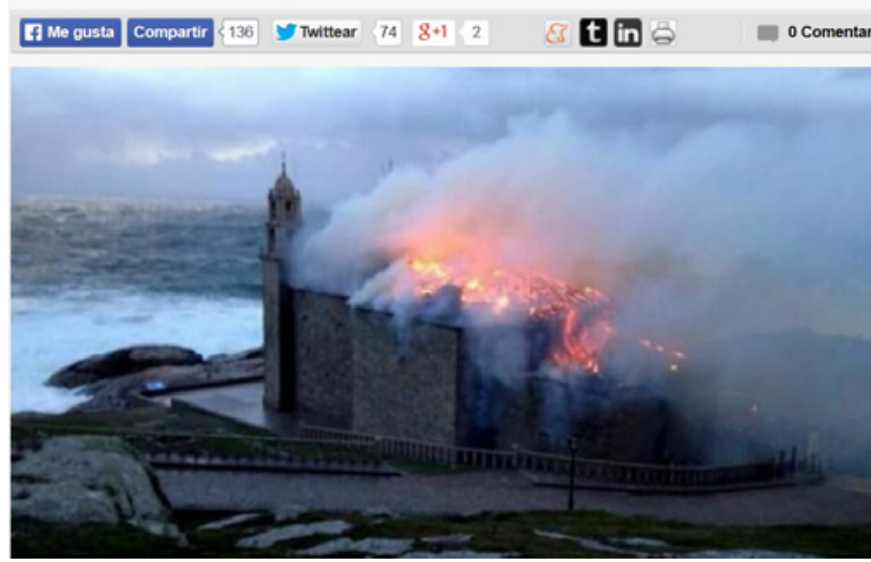

Noticia sobre el incendio del santuario da Virxe da Barca ocurrido el día 25 de diciembre de 2013 | foto laSexta.com

ron sus críticas hacia las personas responsables de las obras de restauración: el vicario del arzobispado, las arquitectas y constructores. Las críticas se centraban en aspectos técnicos como la inadecuación de las maderas y los materiales seleccionados, las deficiencias en los remates y cierres de las puertas, la dificultad añadida para el acceso para personas con movilidad reducida, la humedad que impregnaba los muros y que no había sido eficazmente retirada y que hacía que las paredes continuaran ennegrecidas. También se apelaron a criterios estéticos como el añadido de un recerco de color ocre a la puerta principal, el entarimado de la sacristía, la ausencia temporal de retablo y bancada y, lo que resultó más impactante para los habitantes de Muxía, la elección de un mobiliario de diseño contemporáneo, que era asimilado como "tablas de Ikea". Entre la vecindad que se muestra crítica con el resultado estético también se encuentra el muxián Antón Castro, exdirector del IPCE y doctor en bellas artes, que calificó la obra como kitsch y, en un tono irónico, señaló que no estaba muy alejada de los resultados obtenidos en la restauración del famoso Ecce Homo de Borja. La protesta también fue apoyada por el párroco, que se negó a firmar la recepción de esta primera parte de las obras.

\section{El fuerte oleaje se ensaña con el santuario de Muxía, incendiado en Navidad}

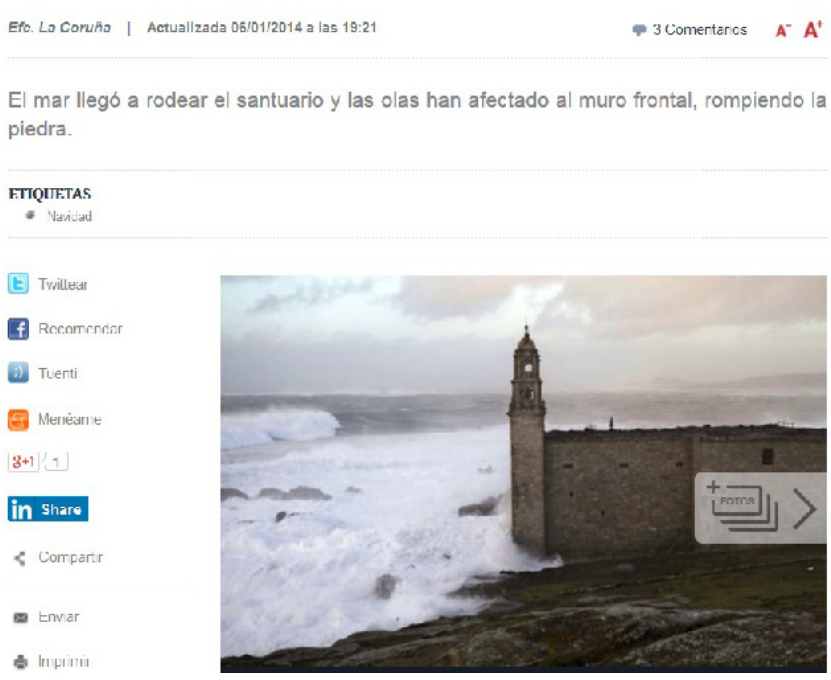

Información en prensa sobre el temporal que afectó al santuario da Virxe da Barca después del incendio, en enero de 2014 | foto HERALDO.es

Pero más allá de la crítica hacia el desarrollo técnico y la resolución estética de la obra, lo que más destacaba es que la ciudadanía apelaba a que el proceso de restauración había pasado por alto tanto el contexto donde se ubica, la identidad del santuario, el "espíritu del lugar" y los vínculos afectivos con el bien (Diario de Campo 27/03/2015). Tampoco se habían tenido en cuenta las opiniones del regidor local, del sacerdote, de la feligresía ni de la población de Muxía que habían permanecido al margen de todo el proceso hasta ese día. Como decía el propio alcalde:

“É bo que escoiten aos veciños porque se non é así volverán cometer exactamente os mesmos erros coa parte que falta por reconstruír. E sabémolo porque algúns quedamos á marxe de todo o que pasou no Santuario".

Desde el INCIPIT, una institución dedicada a la investigación en temas de patrimonio, nos pareció de máximo interés cómo las personas se movilizaron en una reivindicación en torno al patrimonio. Las presentes en la movilización ponían en cuestión los criterios técnicos y criticaban los resultados de la obra de restauración en una performance que tenía elementos propios 


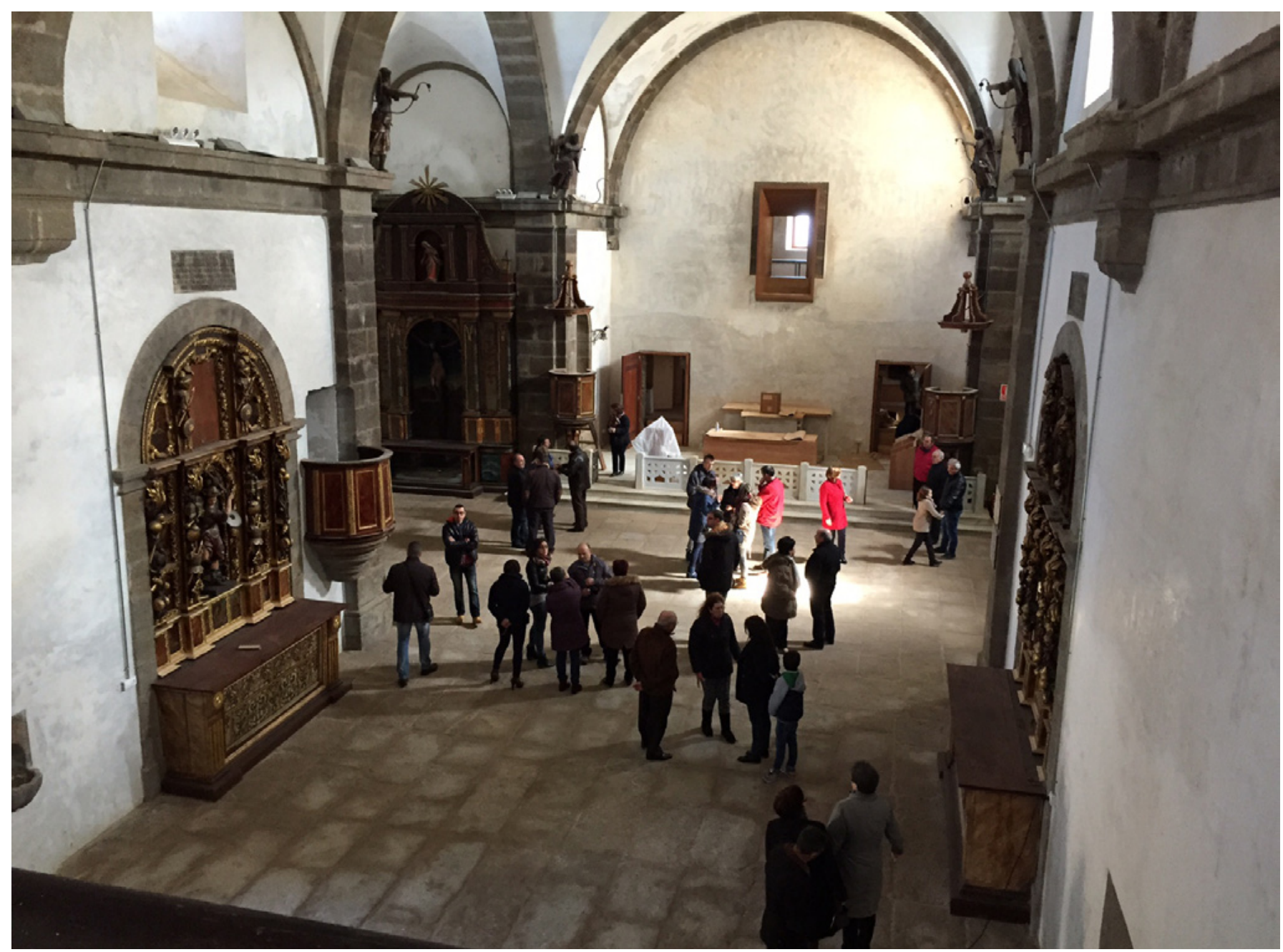

Los vecinos en el interior de la iglesia tras la restauración | foto La Voz de Galicia (Xesús Búa)

de las marchas de los indignados y movimientos ciudadanos como el $15 \mathrm{M}$ y que se desarrolló en el interior del santuario que tanto amaban (DIZ REBOREDO, 2013). Denominaban este referente patrimonial como "un galpón", "corte das vacas", un "sitio indigno", "una chapuza" y plantearon "prenderlle lume outra vez e facelo de novo" delante de las autoridades políticas, religiosas y patrimoniales que habían controlado las obras del santuario en todo momento, sin dar lugar a un intercambio de opiniones con las habitantes de Muxía que ahora planteaban, metafóricamente, incendiarlo de nuevo.

Al contrario de lo que algunas voces críticas querían entresacar de todas aquellas quejas, lo que estaba en ese momento cuestionándose no era sólo el criterio estético sino la opacidad en la toma de decisiones respecto a un santuario que, como decía el alcalde, a pesar de ser propiedad de la iglesia, "tamén é parte de cada unha das casas dos vecinos deste pobo e desta comarca". Como parte del patrimonio de Muxía la vecindad reclamaba formar parte de todo el proceso de toma de decisiones de un elemento que está íntimamente relacionado con la vida de la gente. Que no se les tratase sólo como receptores pasivos de una obra terminada a medias.

Este conflicto en Muxía es una evidencia más de las fracturas o la distancia ontológica existente entre las políticas patrimoniales institucionales, vinculadas a lo 
que Laurajane Smith denomina como "discurso patrimonial autorizado" (SMITH, 2006), y aquello que la gente entiende que es valioso, merece ser mantenido $y$, en este caso concreto, qué criterios deben respetarse en su restauración para que aquel lugar siga siendo parte del patrimonio de la gente de Muxía (ALONSO GONZÁLEZ, 2014; SÁNCHEZ-CARRETERO, 2012).

Desde el punto de vista de las arquitectas y de técnicos de patrimonio de la Xunta, los criterios históricos, técnicos y estéticos que se siguieron para la restauración del santuario están al margen de las opiniones y las decisiones de la ciudadanía. En primer lugar la actuación sobre el santuario no es discutible porque se trata de una propiedad de la iglesia y como tal se ha gestionado al margen de cualquier otra agencia. En segundo lugar porque su rehabilitación obedece a los distintos criterios científicos y técnicos, a la urgencia que precisaba la actuación y a una gestión patrimonial que entiende los bienes como entes desapasionados, con un valor intrínseco ajeno a la interacción social y cultural (DAVALLON, 2010: 42). Como dijo una de las arquitectas de la obra después de las incendiarias reacciones vecinales "la gente valora la obra con el corazón y no con la cabeza, aparte de la técnica influyen mucho los sentimientos de todo el mundo". Esta cita refleja claramente la dicotomía cabeza-corazón que entra en juego al considerar que las decisiones técnicas en temas de patrimonio deben permanecer en manos de técnicos/expertos que usan "la cabeza" y ser alejadas de gente no experta que se guía "por el corazón". El conocimiento y la gestión patrimonial que se concibe como un capital exclusivo del cuerpo (o de la cabeza) de expertos (SMITH, 2006: 11) y excluyente del resto de cuerpos que reclaman su gestión, cuerpos-corazón que incluso ponen en peligro su propio patrimonio que precisa ser salvado, cuerpos sentimentales (HERZFELD, 2004: 198).

Durante un breve trabajo de campo en Muxía los días posteriores a las protestas y en las redes sociales fuimos recogiendo críticas hacia la vecindad de Muxía que era tratada como ignorante y cegada por la beatería, aludiendo a las usuarias de la iglesia que salieron criticando las obras en los medios de comunicación. Las críticas contenían una gran carga sexista y clasista, retratando

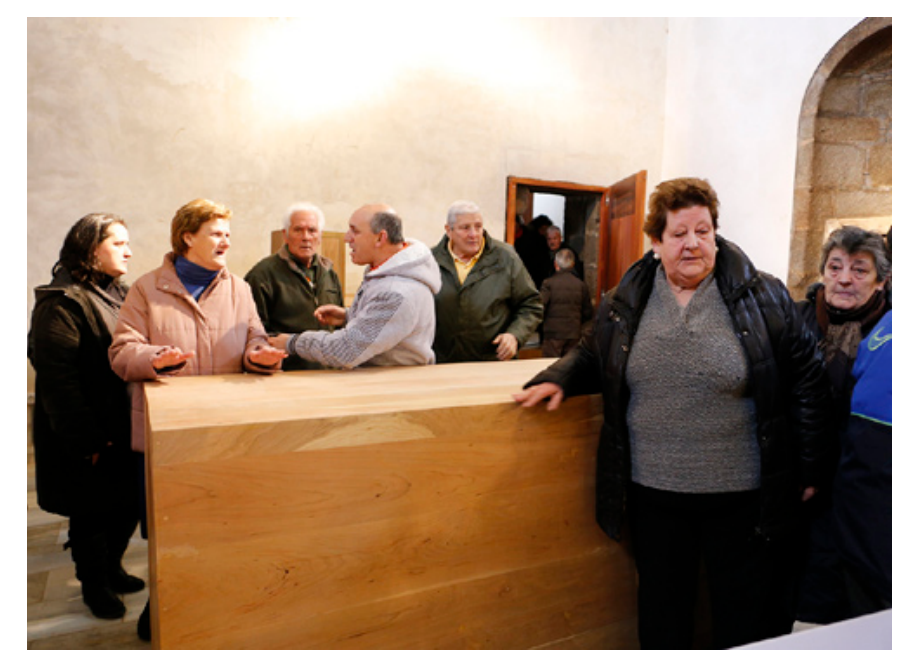

La vecindad de Muxía discutiendo junto al "altar de Ikea" el día de la apertura del Santuario | foto La Voz de Galicia (Xesús Búa)

a la población de Muxía como rural, femenina, vieja y por tanto desconocedora de criterios estéticos y técnicos para la gestión del bien patrimonial. Un lugar poblado de octogenarias que no saben lo que es Ikea y capaces, en su irracionalidad, de amenazar con prender fuego al mobiliario, como retratan algunos medios de comunicación:

"Sin embargo, la propuesta que mayor efusividad desató fue la de retirar toda la carpintería y plantarle fuego. Caló la idea de que está hecha con madera de Ikea y la repetían vecinas octogenarias con dudoso conocimiento de lo que son los muebles de la marca sueca".

Esta performance de la vecindad en el interior de la iglesia y su enfrentamiento a las autoridades religiosas, políticas y patrimoniales evidenció el desencuentro entre el "régimen patrimonial" (BENDIX; EGGERT; PESELMANN, 2012) y las lógicas locales, las fracturas entre las diferentes ontologías patrimoniales (ALONSO GONZÁLEZ, 2013). Pero sin embargo, el tratamiento de la noticia por los medios de comunicación y el cuerpo experto no hizo más que profundizar en las jerarquías entre las distintas posiciones y la marginación de las vecinas en el proceso de toma de decisiones. Sus reacciones apasionadas y emocionales las hacían parecer hostiles e "irremediablemente inferiores" (HERZFELD, 2004: 17) al no participar de la jerarquía de valor, de esos criterios estéticos que se 
aceptan globalmente como una expresión de buen gusto (BOURDIEU, 1998). Según explica la arquitecta sobre la nueva iluminación, "digamos que es lo que se lleva hoy en día en los templos, algo mucho más discreto". La discreción unida a la distinción es lo que expresa el buen gusto para las técnicas encargadas de la remodelación.

\section{Propuesta de mediación en conflictos patrimoniales incendiarios}

Desde los años 90 la perspectiva crítica en el ámbito patrimonial ha propuesto analizar sistemáticamente las claves y los distintos agentes implicados en los procesos de patrimonialización, entendida como una construcción social y política (PRATS, 2004; GARCÍA GARCÍA, 1998; AGUILAR CRIADO, 1999). En esta misma época, de parte de autores como Prats o Cruces (PRATS, 2005: 28; CRUCES, 1998: 78), también se evidenciaba la necesidad de trascender la crítica y hacer propuestas para que la ciudadanía se implicase en la gestión de su patrimonio, cuestionando y dando la vuelta a las patrimonializaciones arriba-abajo.

La tan ansiada implicación de la sociedad con el patrimonio y las reclamaciones por participar en todo el proceso de patrimonialización, desde la selección de bienes, la gestión y la redistribución de beneficios, es ya un hecho creciente y evidente que ahora está desafiando la cultura política y patrimonial y las estructuras de poder que existían hasta el momento (ALCALDE; BURCH; CARBONELL et ál., 2012; ALGUACIL GÓMEZ, 2005; ARRIETA URTIZBEREA, 2009; etc.). En la actualidad, nos encontramos ante la certeza de que existen distintas ontologías patrimoniales (ALONSO GONZÁLEZ, 2013) junto con una explosión de conflictos en torno al patrimonio como escenario político con potencial incendiario. Lo que se nos plantea a la gestión y a la academia del patrimonio es una trascendencia del momento de la crítica patrimonial para establecer cauces en una doble dirección: por una parte, preparar modelos teórico-prácticos de mediación patrimonial $y$, por otra parte, realizar un análisis crítico a los modelos participativos que se están utilizando en la gestión patrimonial.

Desde la antropología y la crítica patrimonial se nos está demandando no sólo realizar una crítica de los desen- cuentros existentes sino analizar las brechas entre agentes sociales, evidenciando la necesidad de encontrar puentes que salven estas fracturas en los conflictos patrimoniales (SÁNCHEZ-CARRETERO, 2012: 206). Con el conocimiento íntimo y profundo de las realidades locales que se alcanza a través del trabajo de campo etnográfico, la antropología y otras ciencias sociales están capacitadas para actuar como figuras de mediación en conflictos patrimoniales.

Existen distintos modelos teóricos y figuras de mediación pero la de la mediación social intercultural, desarrollado hace ya décadas por el antropólogo Carlos Giménez desde la UAM, y de eficacia demostrada en la resolución de conflictos en contextos interculturales en la comunidad de Madrid, nos parece una opción interesante. La aplicación de este modelo de mediación al ámbito patrimonial, algo así como una "mediación patrimonial" (SÁNCHEZ-CARRETERO, 2012: 196), puede ser una herramienta eficaz para mediar en situaciones de conflicto ya que está "orientada hacia la consecución del reconocimiento del Otro y el acercamiento de las partes, la comunicación y comprensión mutua, el aprendizaje y desarrollo de la convivencia, la regulación de conflictos y la adecuación institucional, entre actores sociales o institucionales etnoculturalmente diferenciados" (GIMÉNEZ ROMERO, 1997: 147). No sólo para garantizar la representatividad de la diversidad cultural en contextos multiculturales, como ya planteaban algunos autores en el libro Patrimonio inmaterial y gestión de la diversidad (DIETZ; CARRERA DÍAZ, 2005; CARRERA DÍAZ, 2005; QUINTERO MORÓN, 2005), sino para encontrarse entre distintas instituciones y agentes con aproximaciones al patrimonio totalmente divergentes.

Curiosamente, antes de que se hayan podido implantar modelos de mediación patrimonial en el sentido que exponemos aquí, ya se está consolidando el uso de la expresión "mediación patrimonial" pero con un sentido diferente; para referirse a las visitas a museos diseñadas de forma horizontal partiendo de los intereses del público. Así, el museo de Arte Reina Sofía instauró, desde 2011, la figura del mediador del museo. Según explica la web del museo de Arte Reina Sofía, la finalidad de la mediación cultural es "promover nueva vías de 
comunicación con el visitante y de poner a su alcance los contenidos desplegados, tanto en la Colección, como en las exposiciones temporales". La misma acepción de dinamizador cultural es la que utiliza Medialab-Prado Madrid para sus mediadores: "en el funcionamiento de Medialab es fundamental la labor de los mediadores o dinamizadores culturales, presentes siempre en el espacio de actividades para que este sea un lugar no sólo de emisión de información, sino también de recepción, de encuentro y conexión entre agentes diversos". También hay programas de máster dedicados al tema, como el máster de "Educación y Museos: Patrimonio, Identidad y Mediación Cultural" de la Universidad de Murcia. Es una utilización del término que implica una visión renovada de los servicios de atención al público y la relación entre la creación artística y la sociedad. Sin embargo, no incluyen la idea esencial de la mediación: que el/la mediador/a precisamente se encuentre en una posición intermedia, que medie entre personas o entre alguien (algunas/os) y algo.

En cuanto a la segunda dirección indicada, el análisis crítico de los discursos y las técnicas de participación es el objetivo principal de un proyecto de investigación que estamos iniciando ${ }^{2}$. Este proyecto se plantea un triple objetivo: (1) analizar el papel que están jugando las técnicas participativas en políticas patrimoniales; (2) analizar la vinculación entre participación pública y procesos de patrimonialización; (3) analizar el vínculo entre dicha participación e instituciones patrimoniales. Partimos de la idea de que el previamente mencionado régimen patrimonial (BENDIX, EGGERT; PESELMANN, 2012) o máquina patrimonial (ALONSO GONZÁLEZ, 2013) está creando fracturas sociales estructurales que se reproducen por la propia maquinaria del sistema, independientemente de los elementos o prácticas que se patrimonializan. Una forma de realizar investigación sobre estas fracturas sociales es analizar los numerosos movimientos ciudadanos vinculados a procesos de patrimonialización y los usos de la participación. Se ha podido constatar en investigaciones anteriores que existe un desiderátum de participación social, que, sin embargo, en muchas ocasiones se trasforma en mero maquillaje justificativo. Es decir, las técnicas participativas empleadas en procesos de patrimonialización repro- ducen enfoques no participativos y son usados con finalidad "cosmética" (BENDIX, EGGERT; PESELMANN, 2012; COCA, 2008: 567; QUINTERO MORÓN, 2011; SÁNCHEZ-CARRETERO, 2012). Teniendo en cuenta la importancia de la participación en los modelos alternativos de gestión patrimonial, un paso previo al abordaje de los mismos es conocer los usos, ausencia de usos e instrumentalizaciones de las técnicas participativas en los procesos de patrimonialización.

En el caso concreto de la restauración del santuario da Virxe da Barca en Muxía, las vecinas y los vecinos estaban demandando participar en la gestión de la restauración y en el proceso de toma de decisiones. Para poder implementar formas ágiles de participación, necesitamos, por una parte, conocer los riesgos de su instrumentalización para no reproducirlos; pero también creemos que es un caso que evidencia la necesidad de una figura mediadora que acercase las partes, facilitando la comunicación y la comprensión mutua entre actores sociales e instituciones con unas ontologías patrimoniales diferentes. La mediación patrimonial hubiera sido una forma constructiva de resolver un conflicto que sigue candente desde que un rayo incendiara el santuario el 25 de diciembre de 2013.

\section{NOTAS}

1. Este trabajo se enmarca dentro del proyecto $\mathrm{NEARCH}$ financiado por la programa CULTURA de la Comisión Europea y el proyecto de I+D del Plan Nacional, ParticiPat, "Patrimonio y participación social: propuesta metodológica y revisión crítica” (HAR2014-54869-R).

2. El proyecto de I+D del Plan Nacional "Patrimonio y participación social: propuesta metodológica y revisión crítica" (HAR2014-54869-R) que se inicia en agosto de 2015 se centra precisamente en este tema. El proyecto se coordina desde el INCIPIT (CSIC) y participan diez investigadores e investigadoras de la Universidad Pablo de Olavide, Universidad de Castilla-la-Mancha, Universidad de Santiago y Universidad de Manchester. 


\section{BIBLIOGRAFÍA}

- Aguilar CRIAdo, E. (ed.) (1999) Patrimonio etnológico. Nuevas perspectivas de estudio. Granada: IAPH ; Ed. Comares, 1999

- ALCALDE, G.; BURCH, J.; CARBONELL, E. et ál. (2012) Identificaciones patrimoniales en conflicto. Un análisis a partir de tres casos en Cataluña. Revista Andaluza de Antropología, n. ${ }^{\circ} 2,2012$, pp. $128-148$

- ALGUACIL Gómez, J. (2005) Los desafíos del nuevo poder local: la participación como estrategia relacional en el gobierno local. Polis, 12, 2005, pp. 2-17

- Alonso GonZÁlez, P. (2013) The Heritage Machine: A Heritage Ethnography in Maragatería (Spain). León: Universidad de León, 2013

- ALONSO GoNZÁLEZ, P. (2014) From a Given to a Construct: Heritage as a commons. Cultural Studies, vol. 28 , n. ${ }^{\circ} 3,2014$, pp. 359-390

- ARRIETA URTIZBEREA, I. E. (2009) Activaciones patrimoniales e iniciativas museísticas: ¿por quién? y ¿para qué? Bilbao: Euskal Herriko Unibertsitateko Argitalpen Zerbitzua. Servicio Editorial de la Universidad del País Vasco, 2009

- BENDIX, R.; EGGERT, A.; PESELMANN, A. (2012) Heritage Regimes and the State. Göttingen: Universitätsverlag Göttingen, 2012

- BOURDIEU, P. (1998) La distinción. Criterios y bases sociales del buen gusto. Madrid: Taurus, 1998

- CARRERA díAZ, G. (2005) La evolución del patrimonio (inter) cultural: políticas culturales para la diversidad. En CARRERA DÍAZ, G.; DIETZ, G. C. (coord.) Patrimonio inmaterial y gestión de la diversidad. Sevilla: Consejería de Cultura, Instituto Andaluz de Patrimonio Histórico, 2005, pp. 15-29 (PH Cuadernos; 17)

- COCA, A. (2008) El Plan de Desarrollo Sostenible del Parque Natural de los Alcornocales. En Los Camperos. Territorios, usos sociales y percepciones en un espacio natural andaluz. Sevilla: Fundación Blas Infante, 2008, pp. 557-575

- CRUCES, F. (1998) Problemas en torno a la restitución del patrimonio. Una visión desde la antropología. Política y Sociedad, n. ${ }^{\circ} 27,1998$, pp. 77-87

- DAVALLON, J. (2010) The Game of Heritagization. En FRIGOLÉ, J.; ROIGÉ, $X$. (ed.) Constructing Cultural and Natural Heritage: Parks, Museums and Rural Heritage. Girona: ICRPC, 2010, pp. 39-62

- DIETZ, G.; CARRERA DÍAZ, G. (2005) Introducción En CARRERA DÍAZ, G.; DIETZ, G. C. (coord.) Patrimonio inmaterial y gestión de la diversidad. Sevilla: Consejería de Cultura, Instituto Andaluz de Patrimonio Histórico, 2005, pp. 811 (PH Cuadernos; 17)
- DIZ Reboredo, C. (2013) Políticas del cuerpo y heterotopías del \#15M. Revista de Antropología Experimental [en línea], 2013, n. ${ }^{\circ}$ 13, pp. 89-111 (Etnografías de la indignación) <http://revistaselectronicas.ujaen.es/index.php/ rae/article/view/1896> [Consulta: 06/08/2015]

- GARCÍA GARCÍA, J. L. (1998) De la cultura como patrimonio al patrimonio cultural. Política y Sociedad, n. ${ }^{\circ} 27,1998$, pp. 920

- GIMÉNEZ ROMERO, C. (1997) La naturaleza de la mediación intercultural. Migraciones, n. ${ }^{\circ}$ 2, 1997, pp. 125-159

- HERZFELD, M. (2004) The body impolitic: artisans and artifice in the global hierarchy of value. Chicago: University of Chicago Press, 2004

- PRATS, L. (2004) Antropología y Patrimonio. Barcelona: Editorial Ariel, 2004

- PRATS, L. (2005) Concepto y gestión del patrimonio local. Cuadernos de Antropología Social, n. ${ }^{\circ}$ 21, 2005, pp. 17-35

- QUINTERO MORÓN, V. (2005) El patrimonio intangible como instrumento para la diversidad cultural ¿una alternativa posible? En CARRERA DÍAZ, G.; DIETZ, G. C. (coord.) Patrimonio inmaterial y gestión de la diversidad. Sevilla: Consejería de Cultura, Instituto Andaluz de Patrimonio Histórico, 2005, pp. 69-83 (PH Cuadernos; 17)

- QUINTERO MORÓN, V. (2011) "El patrimonio pertenece a todos". De la universalidad a la identidad, ¿cuál es el lugar de la participación social? En ARRIETA URTIZBEREA, I. (ed.) Legitimaciones sociales de las políticas patrimoniales $y$ museísticas. Abadiño: Universidad del País Vasco, 2011, pp. 45-78

- SÁNCHEZ-CARRETERO, C. (2012) Hacia una Antropología del conflicto aplicada al patrimonio. En SANTAMARINA CAMPOS, B. C. (ed.) Geopolíticas patrimoniales. De culturas, naturalezas e inmaterialidades. Una mirada etnográfica. Valencia: Germania, 2012, pp. 195-210

- SÁNCHEZ-CARRETERO, C. (2012) Heritage Regimes and the Camino de Santiago: Gaps and Logics. En BENDIX, R.; EGGERT, A.; PESELMANN, A. (ed.) Heritage Regimes and the State. Göttingen: Universitätsverlag Göttingen, 2012, pp. 141155

- SMITH, L. (2006) Uses of Heritage. London \& New York: Routledge, 2006 